WHY DO INCREASED ARREST

\author{
RATES APPEAR TO REDUCE CRIME: \\ DETERRENCE, INCAPACITATION, OR \\ MEASUREMENT ERROR?
}

Steven D. Levitt

Working Paper 5268

\author{
NATIONAL BUREAU OF ECONOMIC RESEARCH \\ 1050 Massachusetts Avenue \\ Cambridge, MA 02138 \\ September 1995
}

Anne Piehl and Jon Sonstelie provided extremely helpful comments and discussions. Financial support of the National Science Foundation and the Milton Fund are gratefully acknowledged. All errors are my own. This paper is part of NBER's research program in Public Economics. Any opinions expressed are those of the author and not those of the National Bureau of Economic Research.

( 1995 by Steven D. Levitt. All rights reserved. Short sections of text, not to exceed two paragraphs, may be quoted without explicit permission provided that full credit, including () notice, is given to the source. 


\title{
WHY DO INCREASED ARREST \\ RATES APPEAR TO REDUCE CRIME: DETERRENCE, INCAPACITATION, OR MEASUREMENT ERROR?
}

\begin{abstract}
A strong, negative empirical correlation exists between arrest rates and reported crime rates. While this relationship has often been interpreted as support for the deterrence hypothesis, it is equally consistent with incapacitation effects, and/or a spurious correlation that would be induced by measurement error in reported crime rates. This paper attempts to discriminate between deterrence, incapacitation, and measurement error as explanations for the empirical relationship between arrest rates and crime. Using a modified version of the techniques of Griliches and Hausman (1986) for dealing with measurement error in panel data, this paper first demonstrates that the presence of measurement error does not appear to explain the observed relationship between arrest rates and crime rates. To differentiate between deterrence and incapacitation, the impact of changes in the arrest rate for one crime on the rate of other crimes is examined. In contrast to the effect of increased arrests for one crime on the commission of that crime, where deterrence and incapacitation are indistinguishable, it is demonstrated that these two forces act in opposite directions when looking across crimes. Incapacitation suggests that an increase in the arrest rate for one crime will reduce all crime rates; deterrence predicts that an increase in the arrest rate for one crime will lead to a rise in other crimes as criminals substitute away from the first crime. Empirically, deterrence appears to be the more important factor, particularly for property crimes.
\end{abstract}

Steven D. Levitt

Harvard Society of Fellows

78 Mount Auburn Street

Cambridge, MA 02138

and NBER 
Beginning with the seminal work of Becker (1968), an extensive economic literature has analyzed criminal behavior and issues of criminal justice. ${ }^{1}$ The linchpin of the economic model of crime is the concept of deterrence: rational agents, faced with higher probabilities of detection or more severe sanctions, will commit fewer criminal acts.

In the real world, however, there are a number of obstacles to effective deterrence. First, criminals may be poorly informed about the likelihood of detection, or may be overly optimistic about their own criminal abilities. Second, whereas the benefits of crime accrue immediately, the costs of crime (e.g. imprisonment) are administered with a substantial lag. To the extent that criminals are myopic (Wilson and Herrnstein 1985), even large punishments will have little weight in the current decision of whether or not to commit a crime. Finally, among certain groups, serving time in prison is seen as a rite of passage so that being arrested is sometimes viewed as a positive outcome by the criminal (Venkatesh 1994).

Ultimately, whether deterrence is of practical applicability is an empirical question. Testing for deterrence is difficult because increasing the expected punishment of a criminal act (either through a higher likelihood of detection, or via increased sanctions conditional on being caught), reduces crime in two ways. The first channel is deterrence: larger penalties will lead criminals to commit fewer crimes. The second channel is incapacitation. If criminals commit multiple offenses and punishment takes the form of imprisonment, increasing the expected sanction will also reduce crime by getting criminals off the streets.

1 Notable contributions to this literature include Stigler 1970, Ehrlich 1973, Posner 1977, Blumstein et al. 1978, Witte 1980, Ehrlich 1981, Myers 1983, McCormick and Tollison 1984, Polinsky and Shavell 1984, Andreoni 1991, Waldfogel 1993, and Spelman 1994. 
While a criminal is imprisoned, he is unable to engage in criminal actions that otherwise would have been taken.

The primary source of empirical evidence in favor of deterrence comes from studies that relate measures of the likelihood or intensity of punishment (typically the aggregate arrest rate for a particular crime) to the reported level of that crime. ${ }^{2}$ Consistent with the predictions of the deterrence hypothesis, such studies almost always uncover a negative relationship between punishment and crime rates. There are, however, two major shortcomings of those studies. First, they have no power to differentiate between deterrence and incapacitation effects; both deterrence and incapacitation effects are expected to increase with the expected punishment. Without imposing arbitrary functional form restrictions on the utility function of criminals, it is not clear that the two channels can be distinguished using this approach. ${ }^{3}$ Second, data limitations lead to the possible presence of endogeniety bias in the same direction as predicted by deterrence. The hypothesized relationship in the economic model of crime relates the true arrest rate (arrests/total crimes) to total crime. Because total

2 Blumstein et al. (1978) is an important early contribution to the literature. Gibbs (1986) and Cameron (1988) survey dozens of papers that examine the relationship between aggregate arrest rates and aggregate crime rates. Almost all of the papers surveyed uncover the expected negative relationship. Witte (1980), Viscusi (1986), Trumbull (1989), Grogger (1991), Tauchen, Witte, and Griesinger (1993) find evidence of deterrence effects using either individual level data, or a combination of individual and aggregated data. In contrast, only rarely is a negative relationship observed between the level of police resources and crime rates, although Levitt (1995) is an exception.

3 Also, as demonstrated by McCormick and Tollison (1984), the arrest rate is a very imperfect measure of the likelihood of punishment for a particular crime. Even if the probability of detection for any given criminal act rises, it is theoretically possible that the response of criminals will be to substitute away from the crimes that are most likely to be detected, resulting in a decline in the observed aggregate probability of arrest. 
crimes are not observed by the econometrician, however, the actual measure of both the crime rate and the arrest rate used in empirical studies are computed using reported crimes in place of total crimes. Any measurement error in reported crime will therefore appear both in the left-hand side variable and in the denominator of the right-hand side variable. It is straightforward to show that unlike the standard measurement error case, where the estimated coefficients are typically biased towards zero, measurement error of this type will lead to a negative bias, even if the true coefficients are already negative (Zedlewski 1983; Gibbs and Firebaugh 1990). Given that only thirty-eight percent of all crimes are reported to the police according to victimization surveys (Bureau of Justice Statistics 1994), the potential for measurement error in reported crimes would appear substantial.

This paper attempts to discriminate between deterrence, incapacitation, and measurement error as explanations for the empirical relationship between arrest rates and crime. ${ }^{4}$ The issue of measurement error is addressed first. By comparing parameter estimates generated by models that are differentially affected by measurement error, Griliches and Hausman (1986) provides a means of identifying the presence of measurement error in panel data and obtaining consistent parameter estimates in spite of measurement error. Although the results of Griliches and Hausman (1986) relate to the standard measurement error problem, it is straightforward to demonstrate that their logic extends to the particular

4 Incapacitation in this context refers to "net" incapacitation, i.e. the reduction in aggregate crimes as a result of incapacitation. To the extent that incapacitating one criminal leads to other criminals committing more crimes (e.g. the arrest of one drug dealer may simply lead a second to take his place), net incapacitation effects will be less than the number of crimes the incarcerated individual commits when free. From a social perspective, it is net incapacitation that is relevant. 
measurement problem at hand. First-differenced data is likely to be greatly affected by measurement error because first differencing removes much of the signal, leaving more of the variance to be accounted for by measurement error. Longer differences (e.g. $Y_{t}-Y_{t-n}$ $=\beta\left(\mathrm{X}_{\mathrm{t}}-\mathrm{X}_{\mathrm{t}-\mathrm{n}}\right)$, where $\left.\mathrm{n}>1\right)$ retain more of the signal and therefore should be less biased. Using a panel of city-level arrest data from 1970-1992 for the seven index crimes (murder, rape, aggravated assault, robbery, burglary, larceny and motor vehicle theft), little evidence is uncovered to suggest that measurement error is important in explaining the observed relationship between arrest rates and crime. Moving from first differences to longer differences has no systematic effect on the estimates.

Having addressed the issue of measurement error, the paper turns to the question of deterrence versus incapacitation. Assuming that criminals commit multiple offenses and engage in a range of criminal activities, the response of one crime to changes in the expected punishment for a second crime sheds light on the relative importance of deterrence and incapacitation because those effects have opposite signs. For example, if burglary and larceny are substitutes, deterrence predicts that an increase in the expected punishment for burglary should lead criminals to substitute away from burglaries toward larcenies. Incapacitation effects, on the other hand, imply that an increase in the arrest rate for burglary will lead to a greater number of burglars who are behind bars. Having more burglars locked up should reduce the number of larcenies, assuming that burglars sometimes commit larceny as well. By combining elasticities of crime with respect to own-crime arrests and arrests for other crimes with information about the frequency of crime commission and expected time served, the relative of importance of deterrence and incapacitation can be determined. The 
empirical results suggest that incapacitation predominates for rape, incapacitation and deterrence are of equal magnitude for robbery, and that deterrence effects outweigh incapacitation for aggravated assault and property crimes. Among property crimes, deterrence effects appear to account for more than $75 \%$ of the observed effect of arrest rates on crime.

The results of this paper have important implications for public policy, especially with respect to the policy of "three strikes and you're out." In order for "three strikes" legislation to be an attractive approach to crime reduction, deterrence rather than incapacitation must be the operative factor. If the only effect of increasing the arrest rate is incapacitation, then it would be foolhardy to incarcerate criminals for life since the frequency of criminal activity declines steeply for almost all individuals after the early twenties (Blumstein 1986). In this scenario, a "three strikes" policy would lead to dramatic increases in prison populations, filling the prisons with old men who would not be committing crimes if they were free. In contrast, if the primary effect of the arrest rate is through deterrence, a "three strikes" policy becomes much more attractive. Faced with very stiff penalties, the crime rate will fall, and the overall effect on the prison population is indeterminate (McCormick and Tollison 1984).

The structure of the paper is as follows. Section I addresses the issue of measurement error, generalizing the model of Griliches and Hausman (1986) to the case where the same measurement error is present in both the right-hand side variable and the denominator of the left-hand side variable. The second section presents empirical estimates that suggest that measurement error is not responsible for the observed relationship between arrest rates and reported crime rates. Having addressed the issue of measurement error, the paper attempts 
to distinguish between deterrence and incapacitation as explanations. Section III demonstrates that deterrence and incapacitation have conflicting predictions about the effect of an increase in one crime's arrest rate on the level of other crimes, and uses this insight to estimate the relative magnitude of the two effects. Section IV considers the policy implications of the empirical estimates and offers a brief conclusion.

\section{Section I: Errors-in Variables and the Apparent Effect of Arrest Rates on Crime}

The reliance on reported crime data in estimating the effect of arrest rates on crime may leads to potentially biased estimates if there is measurement error in reported crimes. Assume, for instance, that the true relationship between crime and arrests is as follows:

$$
\ln \left(c_{t}\right)=\lambda \ln \left(\frac{a_{t}}{c_{t}}\right)+\epsilon_{t}
$$

where $t$ indexes time periods, $\mathrm{c}$ is the true number of crimes, $\mathrm{a}$ is the number of arrests, $\epsilon$ is a random noise term. The economic model of crime predicts $\lambda<0$; as the risk of apprehension increases, criminal activity becomes less attractive.

The econometrician does not observe the true number of crimes in equation (1), but rather the number of crimes that are reported to the police. Denoting the number of reported crimes $\mathrm{c}^{\mathrm{r}}$, let this quantity vary according to

$$
c_{t}^{r}=\gamma_{t} c_{t}
$$

where $\gamma_{\mathrm{t}}$ is the percentage of crimes reported to the police in period t. For simplicity, it is 
assumed that the reporting rate $\gamma$ is uncorrelated with the true crime rate, although that assumption is not critical to what follows. Combining equations (1) and (2), the actual specification estimated by the econometrician is

$$
\ln \left(\gamma_{t} c_{t}\right)=\lambda \ln \left(\frac{a_{t}}{\gamma_{t} c_{t}}\right)+\epsilon_{t}
$$

Bias arises because the right-hand side variable of interest, the arrest rate, is defined as the percentage of reported crimes that are cleared by arrest. Any stochastic error in the reporting rate $\gamma_{\mathrm{t}}$ will also appear in the denominator of the arrest rate. Ceteris paribus, when the reporting rate is high, reported crimes are high and the arrest rate is low, inducing a negative bias in $\lambda$. A downward bias in $\lambda$ exaggerates the impact of arrests on the crime rate.

Griliches and Hausman (1986), presents a method that identifies and corrects for the presence of measurement error in panel data. The intuition underlying Griliches and Hausman is that the bias associated with measurement error is sensitive to the choice of estimator. For example, it is well known that estimating with first differences tends to exacerbate the bias due to measurement error. By comparing alternative estimators that are differentially affected by the presence of measurement error, it is possible to determine the extent of the problem and correct for it. More formally, taking the simplest possible case, assume that the true model is as follows: 


$$
y_{i t}=\alpha_{i}+\beta z_{i t}+\eta_{i t}
$$

where $\alpha_{\mathrm{i}}$ are unobserved individual-fixed effects, and $\eta$ is an i.i.d. error term with mean zero and variance $\sigma_{\eta}^{2}$. The underlying $z_{\text {itt }}$, however, are not directly observed. Rather, only an imperfect signal, $\mathbf{x}_{\mathrm{it}}$, is available:

$$
x_{i t}=z_{i t}+v_{i t}
$$

where $\nu$ is an i.i.d. measurement error with variance $\sigma^{2}$.

Finally, assume that, in contrast to the measurement error, the realizations of $z_{i t}$ are positively serially correlated, as is typical in economic time series:

$$
\sigma_{z_{v} x_{t-k}}=\rho^{k}
$$

where $\rho$ is assumed between zero and one. Among the possible sources of such serial correlation are non-stationarity of the underlying process, serial correlation in the shocks that determine $\mathbf{z}_{\mathrm{it}}$, partial adjustment in $\mathbf{z}_{\mathrm{it}}$ due to informational or behavioral lags, or convex adjustment costs in $z_{i t}$.

As Griliches and Hausman demonstrate, it is possible to compare the asymptotic bias in estimates of $\beta$ as one moves from a first difference estimator to second differences (i.e. 
$\left.\mathrm{y}_{\mathrm{it}}-\mathrm{y}_{\mathrm{it}-2}=\beta\left(\mathrm{x}_{\mathrm{it}}-\mathrm{x}_{\mathrm{it}-2}\right)+\eta_{\mathrm{it}}-\eta_{\mathrm{it}-2}\right)$, and other higher order differences. ${ }^{5}$ In particular, the asymptotic bias given equations 4 to 6 is

$$
p \operatorname{plim} b_{j}-\beta=-\frac{\sigma_{v}^{2} \beta}{\sigma_{z}^{2}\left(1-\rho^{\prime}\right)+\sigma_{v}^{2}}
$$

where $b_{j}$ is the parameter estimate of $\beta$ obtained using the $j$-difference estimator.

Measurement error attenuates the estimates of $\beta$ since the bias carries the opposite sign of $\beta$.

As long as $\rho$ is positive and less than one, the asymptotic bias decreases as longer differences are utilized. The changes in the bias can be large: if $\sigma_{z}^{2}$ is five times the size of $\sigma^{2}$, and $\rho=.8,{ }^{6}$ the asymptotic bias of the first difference estimator is $-.5 \beta$, while the asymptotic bias of the fourth difference estimator is approximately half that magnitude.

While the precise results of Griliches and Hausman do not directly apply to measurement error that affects both the right-hand and left-hand side variables presented in equation 3, the intuition does carry over. Algebraic manipulation of equation 3 yields the following analog to equation 7 :

5 Similarly, one can compute the bias of a fixed-effects estimator. The intuition for their result, however, emerges more clearly by comparing short and long differences, so discussion is limited to those estimators. For a more thorough and general treatment, see Griliches and Hausman (1986).

6 For arrest rates, the right hand-side variable of interest in this paper, $\rho$ ranges from .62 to .90 across crime categories when calculated based on variation both across cities and over time. When only within-city variation over time is considered, the correlations range from .36 to .76 . 


$$
\operatorname{plim} \hat{\lambda}_{j}-\lambda=-\frac{\sigma_{\gamma}^{2}(1+\lambda)}{\sigma_{a / c}^{2}\left(1-\rho^{\dagger}\right)+\sigma_{\gamma}^{2}}
$$

where $\lambda_{\mathbf{j}}$ is the estimator based on the jth-difference, $\sigma_{\gamma}^{2}$ is the variance in the reporting rate, $\sigma_{\mathrm{a} / \mathrm{c}}^{2}$ is the variance in the true arrest rate, and $\rho$ is the serial correlation in the true arrest rate. $^{7}$ In contrast to the standard measurement error case presented in equation 7 , errors-invariables in the number of reported crimes leads to a bias that exaggerates rather than attenuates the estimated coefficients, as long as $0>\lambda>-1$ (the likely case when examining elasticities of crime with respect to the arrest rate). As long as $\rho$ is between zero and one, the magnitude of the asymptotic bias declines as longer differences are used. ${ }^{8}$

Section II: Empirical Testing of Arrest Rates in the Presence of Measurement Error

In order to test whether measurement error from the use of reported rather than actual crimes imparts bias on the estimated impact of arrest rates, regressions along the lines of

7 The derivation of equation 8, which is straightforward, is presented in an earlier version of this paper. The intuition for the difference between equations 7 and 8 is as follows. In the standard errors-in-variables case, the measurement error is uncorrelated with the left-hand side variable. Thus, if the measurement error could be separated from the true signal, the coefficient on the measurement error would be zero. The OLS coefficient is a weighted average of the true coefficient and the zero coefficient associated with the measurement error. In the arrest rate case, the measurement error coefficient is -1 (i.e., in the regression $\ln (\gamma)=\beta \ln (1 / \gamma), \beta=-1$ ). As a consequence, the OLS estimate of reported crimes on the arrest rate with reported crimes in the denominator is a weighted average of the true coefficient and -1 .

${ }^{8}$ In the more general case that allows for serial correlation in the measurement error (here the reporting rate), longer differences will be less asymptotically biased as long as the degree of serial correlation in the measurement error is smaller than the serial correlation in the true realization of the right-hand side variable. 
equation 3 were run using annual-level data for 59 of the largest U.S. cities over the period 1970-1992. ${ }^{9}$ Data on reported crime are available from the Federal Bureau of Investigation's Uniform Crime Reports for seven crime categories: murder and non-negligent manslaughter, forcible rape, robbery, aggravated assault, burglary, larceny, and motor vehicle theft. Precise definitions of the various crimes are presented in the appendix. Citylevel arrest data for those crimes, while not published, are also available from the FBI.

In addition to arrest rates, a number of covariates are also included in the estimation of equation 3: year dummies, city population, percent of the city population that is black, percent of the city population residing in female-headed households, percent of the population in the SMSA between the ages of 15 and 24 , the state unemployment rate, combined state and local spending on education, and combined state and local spending on public welfare. All variables are published annually except for $\%$ black, $\%$ in female headed households, and $\%$ age 15-24, which are available only in decennial census years and are linearly interpolated for other years. All demographic variables are published in the Statistical Abstract of the United States. Summary statistics for all of the variables are presented in Table 1.

Table 2 presents crime-by-crime estimates of the coefficient associated with the arrest rate when estimated using first differences through fourth differences of equation 3 . Crime rates and arrest rates are in logs, making the coefficients elasticities. Parameter estimates on

9 The cities included in the sample represent all U.S. cities with a population greater than 250,000 at some point between 1970 and 1992 that have directly elected mayors. While directly elected mayors have no bearing on the analysis at hand, the data were initially collected for Levitt (1995), which was concerned with mayoral elections. Six cities satisfy the population requirement, but are not excluded from the sample due to indirect election of mayors (Cincinnati, Virginia Beach, Norfolk, Wichita, Santa Ana, and Colorado Springs). For more details on the construction of the data set, see Levitt (1995). 
the covariates, which are of only secondary interest, are not presented. ${ }^{10}$ As predicted by the economic model of crime, all of the coefficients are negative: an increase in the likelihood of arrest for a given crime decreases the amount of that crime. The coefficients, which are elasticities, vary between -0.030 to -0.319 . In almost all cases, the estimates are statistically different from zero.

If measurement error resulting from the use of reported crime is a problem, one would expect the coefficients to be monotonically declining in magnitude moving from column 1 to column 4 in Table 2 since longer differences should be less sensitive to measurement error. For only one of the seven crime categories, auto theft, is that pattern observed. In fact, for three crime categories (robbery, burglary, and larceny) the opposite pattern emerges, with each column more negative than the preceding one. For the other categories, there appears to be little systematic change in the coefficients moving from left to right in the table. Comparing columns 1 and 4 , the estimates differ at the .05 significance level only for robbery, burglary, and larceny - the three categories that exhibit the unexpected pattern of coefficients.

The results of Table 2 are initially perplexing in that they not only reveal no systematic evidence of measurement-error bias, but also show an unexpected increase in coefficients as longer differences are employed. One plausible explanation for the observed pattern of coefficients is a lag in the response of crime rates to changes in the arrest rate. Such lags might arise for two reasons. First, if criminals are poorly informed about the true

10 Complete results are available from the author on request. Also, Table 4 presents estimates of the coefficients on the covariates for an expanded, but similar, specification. 
likelihood of arrest, one might expect to observe a gradual change in criminal behavior in response to increased law enforcement. Second, if criminals are repeat offenders, the fact that some criminals arrested in one year are convicted and serve prison terms that run into the following year, leads to a dependence of this year's crime rate on last year's arrest rate. Assume, for instance, that the true relationship between the crime rate and the arrest rate is given by the following equation

$$
c_{i t}=\alpha_{i}+\lambda\left(\frac{a_{i t}}{c_{i t}}\right)+\theta\left(\frac{a_{i t-1}}{c_{i t-1}}\right)+\epsilon_{i t}
$$

so that both the current arrest rate and the once-lagged arrest rate affect the current crime rate. The a priori expectation is that both $\lambda$ and $\theta$ will be negative, meaning that higher arrest rates reduce crime both contemporaneously and with a lag. Ignoring the measurement problem associated with the use of reported crime, which continues to enter in the same manner as previously, it is straightforward to calculate the bias in the coefficient $\lambda$ when the specification employed is equation 3, when in fact equation 9 is the true model:

$$
\operatorname{plim} \hat{\lambda}_{j}-\lambda=-\theta\left[2 p-\rho^{(j-1)}-\rho^{(j+1)}\right]
$$

where the subscript $\mathrm{j}$ again refers to the $\mathrm{j}$-difference estimator. Further manipulation of 
equation 10 reveals that the bias in equation 10 is upwards for the first-difference estimator, but downward for higher differences, as long as $\theta<0$ and $\rho>0 .{ }^{11}$ The difference in the estimates can be significant. Assuming that $\theta=-.1$ and $\rho=.8$, the asymptotic bias in equation 10 is +0.004 for the first-difference estimator, and -0.076 for the fourth difference estimator. The gap between those biases is the same order of magnitude as the observed differential in the coefficients in columns 1 and 4 for robbery, burglary, and larceny, and thus provides a theoretical explanation for the observed pattern of coefficients.

Table 3 replicates the regressions of Table 2 except that the once-lagged arrest rate is also included as a regressor. The coefficients reported in Table 3 are the sum of the contemporaneous and once-lagged arrest rate elasticities and therefore represent the two year effect on crime of one-year's increase in the arrest rate. The coefficients in Table 3 continue to fail to reveal any systematic decline in coefficients moving left to right. The surprising pattern of increasing coefficients observed in Table 2, however, is now eliminated with the addition of once-lagged arrest rates. ${ }^{12}$ For none of the seven crime categories can the null hypothesis of equal coefficients across the four columns be rejected at the $5 \%$ level.

In summary, two conclusions emerge from the this analysis of the possible effects of measurement error resulting from the use of reported crime. First, there is little evidence

11 Of course, equation 10 ignores the downward bias resulting from errors-in-variables. Therefore, the overall sign of the bias in the arrest-rate coefficient from estimating equation 3 in first differences is indeterminate. For higher order differences, the sign of the bias is unambiguously negative.

12 As would be expected from a comparison of the estimates across the two tables, the coefficient on lagged arrest rates are negative and statistically significant for robbery, burglary, and larceny, and statistically insignificant for the other crimes. 
that the use of reported crime rates induces a substantial bias in the estimated effects of arrest rates since estimators that are differentially affected by such bias yield very similar results. ${ }^{13}$ Second, lagged arrest rates appear to have systematic effects on the crime rate (at least for robbery, burglary, and larceny). While that result is not completely inconsistent with the economic model of crime, it suggests that either incapacitation effects, imperfect information, or partial adjustment of behavior on the part of criminals are present, factors that are often ignored. The following section presents a methodology for distinguishing between deterrence and incapacitation, ignoring measurement considerations from this point.

Section III: Differentiating between Deterrence and Incapacitation

Having demonstrated that measurement error does not appear to explain the observed relationship between arrest rates and crime rates, the analysis turns to differentiating between the two remaining explanations: deterrence and incapacitation.

It is impossible to determine whether the negative correlation between arrest rates and crime in Tables 2 and 3 is the result of deterrence or incapacitation without further analysis. Both channels are a function of the expected penalty (i.e. likelihood of detection * punishment if detected), and in many specifications the two are perfectly collinear when looking at the effect of the own-crime arrest rate on the crime as long as punishment is in the

${ }^{13}$ Levitt (1994) examines the question of whether crimes are more likely to be reported to the police when the size of the police force increases and finds very small effects. That analysis, like this one, concludes that the use of reported crime statistics is less problematic than was previously thought. 
form of incarceration.

Examining the effect of changes in the arrest rate for one crime on the rate of commission a second crime, however, allows deterrence and incapacitation effects to be separately identified. ${ }^{14}$ As long as criminals are repeat offenders and do not specialize in one particular type of crime, an increase in the arrest rate for any one crime will lead to a reduction in all crimes due to the incapacitation effect. In contrast, if criminals are rational and different crimes are substitutes for one another, the deterrence effect implies that increasing the arrest rate for one crime will lead to a decrease in that crime, but an increase in other crimes as criminals substitute away from the first crime, the "price" of which has risen. Because the sign of deterrence and incapacitation conflict when looking at the acrosscrime effect of changes in the arrest rate, it is possible to ascertain their relative magnitudes.

While it is possible to construct a formal model capturing this intuition, the underlying logic is so straightforward that such an exercise does not seem warranted. It is nonetheless important to (1) be clear about the precise assumptions that are necessary for the analysis, and (2) examine the plausibility of those assumptions.

In order for there to be an incapacitation effect, criminals must be repeat offenders. The evidence supporting that assumption is overwhelming; surveys of prisoners find that the median number of non-drug crimes committed in the year preceding their most recent arrest is twelve to fifteen (Visher 1986, Dilulio and Piehl 1993, Piehl and Dilulio 1995). For across-crime incapacitation effects to be present, individual criminals must engage in multiple

14 Benson et al. (1995) looks at cross-crime effects of arrest rates in a different context, but does not examine the implications for distinguishing between deterrence and incapacitation. 
types of criminal activity. If a cat-burglar only burgles, then his arrest would not be expected to reduce the number of robberies or assaults. The evidence suggests that the preponderance of criminals are in fact generalists (Beck 1989). Only one in twenty released murderers who recidivate will be rearrested for the same crime. The corresponding number for released robbery and auto theft is less than one in three; for burglary and larceny, it is slightly less than one in two.

For deterrence effects to be present across crimes, a change in the likelihood of arrest for one crime must affect the frequency of commission of a second crime. ${ }^{15}$ For certain pairs of crimes, such as murder and larceny, it is hard to imagine that there is any substitution across categories. The various property crimes, on the other hand, are likely to be substitutes. If the primary reward of property crimes is the monetary value of the stolen property, then property crimes will be substitutes as long as the marginal utility of income is decreasing. In the extreme case of target incomes (perhaps a reasonable description of the behavior of drug addicts who need a given level of income to support their habit), any deterrence arising from greater enforcement against one type of crime will be completely offset by increases in other crimes. To the extent that the various types of violent crime are different manifestations of underlying aggression, one would also expect violent crimes to be

15 Note that this is a much stronger condition than simply asserting that the same people who sometimes commit assaults also sometimes steal cars. Rather, what is required is substitutability in the microeconomic sense of the word.

A second requirement is that changes in recorded arrest rates are not just noise, but instead reflect real variation in the likelihood of being arrested. To the extent that this is not true, deterrence effects will tend to be understated. 
substitutes for one another. ${ }^{16}$

Figure 1 summarizes the predictions of the model, and also serves as a guide for the empirical work that follows.

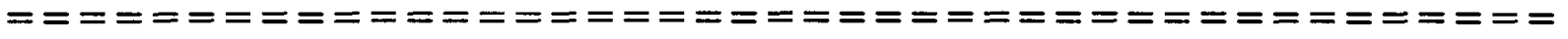

Figure 1: Predicted Effects of Changes in Arrest Rates through

Deterrence and Incapacitation Channels

Own Crime

Arrests
Non-Substitutable

Crime Arrests
Substitutable Crime Arrests

Deterrence

0

$+$

Incapacitation

Overall

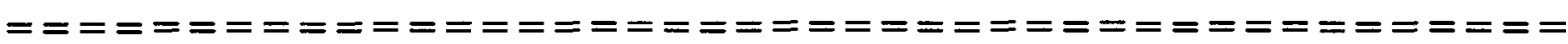

The sign of the deterrence effect depends on the relationship between the crimes.

Deterrence is negative in the own-crime arrest rate, non-existent if the crimes are not substitutes, and positive when the crimes are substitutes. For the purposes of the empirical analysis, it is assumed that violent crimes are substitutes for each other, and property crimes are substitutes for each other, but that violent and property crimes are not substitutes for one another. Regardless of the relationship between two crimes, the incapacitation effect always

16 One could also imagine that certain types of crimes might be complements. For instance, to the extent that alcohol generally raises the propensity to commit crimes, increased enforcement of public drunkenness or driving under the influence laws might be expected to reduce the rate of other crimes. For the index crimes, however, the conditions for crimes being complements are unlikely to be met. Moreover, since Uniform Crime Reports record only the most serious offense when multiple crimes are committed in one incident, the complement condition is even more unlikely. 
works to reduce the crime rate. ${ }^{17}$

To test the above arguments, a variation of equation (9) which also includes the contemporaneous and once-lagged arrest-rates for other crimes is estimated as follows:

$$
c_{i t}=\alpha_{i}+\lambda\left(\frac{a_{i t}^{o}}{c_{i t}^{o}}\right)+\theta\left(\frac{a_{i t-1}^{o}}{c_{i t-1}^{o}}\right)+\phi_{s}\left(\frac{a_{i t}^{s}}{c_{i t}^{s}}\right)+\phi_{n}\left(\frac{a_{i t}^{n}}{c_{i t}^{n}}\right)+\kappa_{s}\left(\frac{a_{i t-1}^{s}}{c_{i t-1}^{s}}\right)+\kappa_{n}\left(\frac{a_{i t-1}^{n}}{c_{n t-1}^{n}}\right)+X_{i t}^{\prime} \beta+\epsilon_{i t}(11)
$$

where the subscript $\mathrm{i}$ indexes cities, and $\mathrm{t}$ reflects time periods. The superscript $\mathrm{o}$ corresponds to own-crimes, $\mathrm{s}$ refers to crimes that are substitutes for crime $\mathrm{o}, \mathrm{n}$ represents crimes that are not substitutes for crime $o . c_{i t}$ and $a_{i t}$ are the number of reported crimes and arrests respectively. $X_{i t}$ is the same vector of covariates included in the earlier regressions. In the actual estimation, both crime rates and arrest rates are logged, making the coefficients elasticities.

Estimates of equation 11, using the same data employed previously, are presented in Table 4. The arrest-rate coefficients in Table 4 are the sums of the coefficients on the

17 If two crimes are actually substitutes, but are treated as if they are not substitutes, the estimated incapacitation effect will be too small. Robbery is the one crime category for which this assumption is most difficult to justify. Following the FBI, robbery is classified as a violent crime. A primary objective of robbery is monetary gain, however, giving it a similarity with property crimes. Classifying robbery as a property crime does not substantively alter the conclusions of the analysis.

If two crimes are not substitutes, but are classified as substitutes, the analysis that follows is not biased since the identification of the parameters comes only from the coefficient on crimes classified as non-substitutes. The estimates will, however, be less efficient than if the categorization had been done correctly. 
current and once-lagged arrest rates. ${ }^{18}$ The signs of the estimated parameters correspond closely to the predictions in Figure 1. A negative relationship between crime rates and owncrime arrest rates crime exists for six of the seven categories, with murder, which is positive and insignificant, being the only exception. Comparing the results of Table 3 to the top row of Table 4, the individual elasticity estimates change somewhat, but are not systematically increased or reduced by the inclusion of arrest rates for other crimes, or by the use of a fixed-effects model in place of differenced data.

The second row of Table 4 presents the elasticities of the various crimes with respect to the arrest rates for crimes that are assumed not to be substitutes. For such crimes, there should be only incapacitation effects, and thus the expected sign of the coefficients is negative. For all seven crime categories, the point estimate is in fact negative, although the coefficients are statistically significant from zero in only two cases (robbery and rape).$^{19}$

The third row of Table 4 presents the estimated elasticities of crime with respect to arrests for crimes that are potential substitutes for the crime in question. The expected sign on such parameters are theoretically ambiguous since deterrence operates in a positive direction and incapacitation implies a negative sign. In practice, the sign on these coefficients are mixed, with three negative and statistically significant, two positive and

${ }^{18}$ Adding longer lags had little effect on the total estimated elasticity of crime with respect to the arrest rate. Thus, these elasticities can be interpreted as long-run elasticities.

19 Since non-substitutable crimes operate only through incapacitation, total arrests rather than arrest rates might seem to be the more appropriate explanatory variable. A problem with total arrests, however, is that it is likely to be an increasing function of the number of crimes committed. If the random component of the various crime categories are correlated with in a city, then the coefficient on actual arrests for the non-substitutable crimes will be biased upwards, whereas the coefficient on the arrest rate will not. 
statistically significant, and two statistically insignificant coefficients.

The other coefficients in the model appear generally plausible as well. \% femaleheaded households and \% black enter positively with only a few (statistically insignificant) exceptions. Increases in the \% age 15-24 leads to higher crime rates in 5 of the 7 cases. Public welfare spending has mixed effects. Surprisingly, education spending per capita enters positively, perhaps suggesting that educational outlay is a better proxy for the age distribution than the variable \% age $15-24$, which is interpolated from the decennial census. High unemployment rates are associated with increases in crimes where monetary gain is the objective, but are negatively related to other crimes.

\section{Using these estimates to determine the relative importance of}

\section{deterrence and incapacitation}

The estimated elasticities in Table 4, while critical components, are not sufficient by themselves to decompose the own-arrest elasticity into deterrence and incapacitation effects. To do so requires estimates of two other factors: (1) the proclivity of criminals arrested for one crime to engage in other criminal activities, and (2) the expected length of incapacitation associated with an arrest for a particular crime. Formally, let the reduction in the number of reported crimes in category $i$ associated with one additional arrest for crime $j$ (evaluated at the means of the data) be denoted $\mathrm{INCAP}_{\mathrm{ij}}$. Define RATE $_{\mathrm{ij}}$ as the rate at which criminals arrested for crime $\mathrm{j}$ commit crime $\mathrm{i}$ when not incarcerated. RATE $_{\mathrm{ii}}$ is likely to be greater than $\operatorname{RATE}_{\mathrm{ij}}$ for $\mathrm{j} \neq \mathrm{i}$, but all RATEs will be positive as long as criminals are generalists. Finally, let TIME_SERVED ${ }_{i}$ be defined as the expected time served conditional on being 
arrested for crime $\mathrm{i}^{20}{ }^{20}$ The incapacitation effect per own-crime arrest, INCAP ii $_{\text {(in terms of }}$ crimes eliminated per arrest), can then be expressed as

$$
I N C A P_{i i}=I N C A P_{i n} * \frac{R A T E_{i i}}{R A T E_{i n}} * \frac{T I M E \_S E R V E D_{i}}{T I M E \_S E R V E D_{n}}
$$

While INCAP $_{\mathrm{ii}}$ is not directly observable, INCAP $_{\text {in }}$ is, where the subscript $\mathrm{n}$ corresponds to non-substitutable crimes is estimated in the second row of Table 4. The two ratios on the right hand-side of equation 12 can be approximated from existing data sources. Therefore, INCAP $_{i i}$, the number of crimes eliminated per arrest that can be attributed to incapacitation, can be determined. The more specialized criminals are, the larger is $\operatorname{INCAP}_{\text {ii }}$ relative to INCAP $_{\text {in }}$; assuming a constant rate of crime commission, the relative magnitude of the incapacitation effect per arrest will be proportional to the average length of time behind bars per arrest.

Given equation 12 , the deterrence effect (in terms of crimes eliminated per arrest) is simply

20 Technically, this analysis will only be concerned with time served within two calendar years of an arrest because only one lag of the arrest rate is included in the specifications estimated. 


$$
D E T E R_{i i}=T O T A L_{i i}-I N C A P_{i i}
$$

where TOTAL $_{\mathrm{ii}}$ is the total reduction in crime $\mathrm{i}$ eliminated per arrest for crime $\mathrm{i}$ from Table 4 , evaluated at the sample means.

Estimates of the two ratios in equation 12 are available in existing sources. Table 5 details the information required to compute a rough estimate of the time behind bars per arrest for the various crimes using information compiled in the FBI's Uniform Crime Reports and the Bureau of Justice Statistics' Felony Defendants in Large Urban Counties, $1990 .{ }^{21}$ Column 1 presents the relative number of arrests for the various index crimes, using murder arrests as a baseline. For every murder arrest, there are 1.6 arrests for rape, 8.5 robbery arrests, and more than 80 larceny arrests. Only adjudicated cases are likely to result in significant time served. As column 2 demonstrates, arrests for less serious crimes are less likely to lead be adjudicated. ${ }^{22}$ Although there are twenty times as many arrests for aggravated assault vis-a-vis murder, only twelve times as many arrestees are prosecuted. For larceny and theft, those arrested are only one-sixth as likely to be prosecuted as those arrested for murder.

Time served can be decomposed into two components: time served before and after sentencing. Column 3 of Table 5 presents the average time between arrest and sentencing

21 Larceny and other theft, including auto theft, are not separately broken out in the study of felony defendants. In what follows, I assume that an arrest for larceny and auto theft are the same.

22 The values in column 2 apply only to felony defendants. A small fraction of arrests for index crimes lead to misdemeanor charges. Misdemeanor charges are not included in this calculation. 
for the different crime categories. Only a fraction of defendants are detained pre-trial, however, as reported in column 4 . Column 5 reports the average pre-sentence time behind bars per arrest, assuming that (1) arrestees that are not prosecuted are released soon after their arrests, (2) all murder arrests lead to adjudication, (3) pre-trial releasees are released immediately, ${ }^{23}$ and (4) the expected wait to sentencing is the same for those who obtain pretrial release and those who are detained. ${ }^{24}$ Murder arrests lead to an average of 232 days of pre-trial incapacitation, more than twice the amount of any other crime. Rape and robbery arrests result in an average of approximately 100 days behind bars prior to sentencing. In contrast, those arrested for aggravated assault spend about one month behind bars prior to sentencing, and those accused of larceny spend only ten days.

Column 6 of Table 5 presents the fraction of felony defendants who are convicted and sentenced to serve time behind bars. Column 7 contains the estimated time behind bars postsentencing per arrest within two calendar years of arrest. Because only contemporaneous and once-lagged arrest rates are included in the regressions, only incapacitation effects within two calendar years of arrest are relevant to the calculations. Given that the average time to sentencing is over half a year, and that the typical prisoner will be arrested six months into the calendar year if arrests are uniform across months, the maximum possible average post-

$2380 \%$ of those receiving pre-trial release are free within a week of arrest.

24 The assumption that all murder arrests lead to adjudication will tend to slightly exaggerate the calculation of time served per arrest, while ignoring the time served by arrestees against whom charges are eventually dropped and the time served pre-trial among those receiving pretrial release will bias the results in the opposite direction.

The actual values in column 5 are computed as the product of columns 3 and 4 times the ratio of column 2 to column 1 . 
sentencing time behind bars within two calendar years of arrest is one year. For convicted criminals, I assume that this maximum value applies. This assumption will tend to overstate the amount of incapacitation for minor crimes, where shorter sentences are sometimes handed down. Even for larcenists, however, the mean sentence among those sentenced to serve time is 35 months, suggesting that any distortion due to this assumption is likely to be minimal. ${ }^{25}$

The second factor that needs to be taken into account in determining the relative importance of deterrence and incapacitation is the proclivity of different types of criminals to commit various crimes. Recidivism data suggests that criminals arrested for a particular crime are more likely than other criminals to be re-arrested for the same crime upon their release. Table 6 presents the probability that a criminal serving time for different crimes will be arrested for each index crime within three years of release. The data in Table 6 is based on a study of more than 16,000 prisoners released in 1983, as reported in Beck (1989). $6.6 \%$ of convicted murderers will be arrested for murder within three years of release. In contrast, only $1.0 \%$ of those convicted of property crimes will be arrested for murder. Similarly, $18.6 \%$ of convicted auto thieves are re-arrested for this offense, compared to only $4.2 \%$ of violent offenders.

Table 7 combines the information in Tables 4-6 to generate estimates of the relative magnitudes of incapacitation and deterrence. Column 1 is the total reduction in a given crime associated with an additional own-crime arrest (evaluated at the means of the data).

${ }^{25}$ The value in column 7 is computed as 365 days times column 6 , multiplied by the ratio of column 2 to column 1 . 
Column 2 is the estimated reduction in crime per arrest for non-substitutable crimes, which reflects only incapacitation effects. Columns 3 and 4 report the required adjustment factors from equation 11 . Column 3 is the ratio of time served by those arrested for the crime in question versus the non-substitutable crimes from Table 5; Column 4 is the relative rate at which the crime is committed by arrestees for this crime and arrestees for the nonsubstitutable crime, based on Table $6 .{ }^{26}$ Columns 5 and 6 present the breakdown between incapacitation and deterrence effects, using the information in columns 1-4 and equations 11 and 12. Standard errors are reported, assuming that the only source of error arises from the estimation of the elasticities. These standard errors (perhaps vastly) understate the true variability in the estimates since the information in Tables 5 and 6 is also subject to error, the magnitude of which is unknown.

A comparison of columns 5 and 6 of Table 7 suggests that deterrence is generally more important than incapacitation, particularly for the less serious crimes. For murder, large standard errors make strong conclusions impossible; neither channel is statistically significant. Rape and robbery are the only crime categories for which incapacitation is statistically significant, with more than half a crime eliminated per arrest due to incapacitation. For all crime categories except murder and rape, deterrence effects are statistically significant at or near the $5 \%$ level and carry the expected sign. For property crimes and assault, deterrence is as much as an order of magnitude greater than incapacitation, explaining a minimum of $75 \%$ of the overall effect. Although these four

${ }^{26}$ Because column 4 compares the rate at which different offenders commit the same crime, there is no need to adjust for differences in arrest rates across crimes. 
crimes are less severe, they account for over $90 \%$ of all index crimes. The largest deterrence effect is for burglary: an additional arrest eliminates two burglaries through deterrence, compared to only -.10 via incapacitation. The results obtained here are consistent with Ehrlich (1981) which finds that deterrence is more important than incapacitation.

Given the number of assumptions underlying the results in Table 7, it is worthwhile considering two rough checks on the plausibility of the estimates of the deterrence and incapacitation effects. The first check is a comparison of the magnitude of incapacitation effects found here to the results from prisoner surveys (Visher 1986, Dilulio and Piehl 1993, Piehl and Dilulio 1995). Combining the estimated own-arrest incapacitation effect with the information on the relative frequency of crime commission for those arrested for different crime categories, it is possible to come up with estimates of the total number of crimes eliminated (in all categories) per year behind bars. ${ }^{27}$ To make this calculation comparable to the prisoner self reports, an adjustment for crime reporting is required since victimization surveys suggest that only $38 \%$ of all index crime victimizations are reported to the police (Bureau of Justice Statistics 1994). After adjusting the reported crime rates to reflect victimizations, the estimated reduction in index crimes associated with an additional personyear of incapacitation at the margin ranges between 5.1 and 8.2, depending on the crime category of the arrest. Those values are somewhat lower than, but the same order of

27 This estimate is obtained by first calculating the number of own-crimes eliminated through incapacitation per person-year behind bars using column 8 of Table 5 and column 6 of Table 7. Those values are then combined with the relative proclivities of offenders arrested for particular crimes to engage in other crimes to obtain the total number of crimes eliminated by incapacitation per year behind bars. 
magnitude as, prisoner self reports: the median prisoner reports involvement in 12-15 index crimes per year when free. The difference between the estimates obtained here and prisoner self reports may be attributed to a number of sources. First, criminal acts frequently involve multiple perpetrators (Spelman 1994); incarcerating one of the offenders may not prevent a crime's occurrence. Second, to the extent that there are "replacement" effects, removing one criminal from the street will lead other criminals to commit some crime's previously committed by the incarcerated offender. Both of those factors imply that the total number of crimes will fall by less than the number that would have been committed had the offender not been incarcerated. Finally, given the skew in criminal involvement, the marginal criminal arrested is likely to be less criminally active than the median prisoner. Even ignoring these three explanations, it is clear that doubling or tripling the magnitude of the incapacitation effects obtained in this paper still leaves deterrence as the primary explanation for the reduction in crime associated with increased arrest rates for property crimes.

A second informal check on the validity of the results involves calculating the implied deterrence effects using the cross-crime elasticities from substitutable crimes, assuming that there is no substitutability. To the extent that this assumption is false, this approach should understate incapacitation effects since incapacitation and deterrence push in opposite directions, and this assumption assigns both effects to incapacitation. The results are fairly similar to those in Table 7. For murder and aggravated assault, the estimates of deterrence are almost identical ( -.036 vs -.030 and -.014 vs -.034 , respectively). The incapacitation effect for rape falls nearly to zero (-.014). and for larceny goes from a slight negative to a slight positive (.278). Burglary and auto theft both exhibit larger incapacitation effects (-.758 
and -.569). Robbery, on the other hand, goes from a negative to positive incapacitation effect. Overall, while some coefficients increases and others decrease, the net change is approximately zero.

\section{Section IV: Conclusions}

Negative correlations between arrest rates and crime rates are consistent with deterrence effects, incapacitation effects, and measurement error in reported crime. This paper has explored those three possible explanations, concluding that there is little evidence that measurement error is responsible for the observed relationship between arrest rates and crime rates, and that deterrence appears to be empirically more important than incapacitation in reducing crime, particularly in the case of property crimes.

From a public policy perspective, the distinction between deterrence and incapacitation is an important one. If incapacitation is the primary source of crime reduction, a "three strikes" policy is likely to be both costly and inefficient. The total number of prisoners will increase dramatically under such a scenario, with the prison population increasingly composed of aging, low-risk inmates who pose little threat to society if released. In contrast, if deterrence is strong enough, "three strikes" policies can actually lead to a reduction in total time served: the decline in criminal acts can be great enough to offset the longer punishments meted out when a criminal is arrested (McCormick and Tollison 1984).

If the large deterrence effects found in this paper are correct, then one would expect to see reductions in crime accompanied by relatively small increases in prison populations in 
states where "three strikes" has been implemented. The early experiences with "three strikes" policies appear consistent with this prediction. Washington state, whose voters passed a "three strikes" law in 1993, has seen a drop in violent crime and projects the need for only a $10 \%$ increase in prison capacity over the next ten years; California saw a $7.2 \%$ decline in violent crime in the first year under "three strikes" and the California Department of Corrections recently reduced its projection of the increase in prisoners due to the policy by $25 \%$ (USA Today, July 6,1995 ). 


\section{Definitions of the Uniform Crime Reports Crime Categories}

Murder and Nonnegligent Manslaughter

The willful killing of one human being by another. Deaths caused by negligence, attempts to kill, assaults to kill, suicides, accidental deaths, and justifiable homicides are excluded. Justifiable homicides are limited to the killing of a felon. Traffic fatalities are excluded.

\section{Forcible Rape}

The carnal knowledge of a female forcibly and against her will. Included are rapes by force and attempts or assaults to rape. Statutory offenses (no force used -- victim under age of consent) are excluded.

\section{Robbery}

The taking or attempting to take anything of value from the care, custody, or control of a person or persons by force, or threat of force, or violence, and/or by putting the victim in fear.

\section{Aggravated Assault}

An unlawful attack by one person upon another for the purpose of inflicting severe or aggravated bodily injury. This type of assault usually is accompanied by the use of a weapon or by means likely to produce death or great bodily harm. Simple assaults are excluded.

Burglary

The unlawful entry of a structure to commit a felony or a theft. Attempted forcible entry is included.

\section{Larceny}

The unlawful taking of property from the possession of another. Examples are thefts of bicycles or automobile accessories, shoplifting, pocket-picking, or the stealing of any property or article which is not taken by force and violence or by fraud. Attempted larcenies are included. Embezzlement, "con" games, forgery, and worthless checks are excluded.

\section{Motor Vehicle Theft}

The theft or attempted theft of a motor vehicle. 
Table 1: Summary Statistics

Per 100,000 Residents where Applicable

$\underline{\text { Variable }}$

$\underline{\text { Mean }}$

Standard

\section{Reported Crime Rates}

Murder

18.9

69.7

12.3

Rape

562.7

31.0

Robbery

531.7

378.1

Agg. Assault

355.7

Burglary

$2,324.3$

726.6

Larceny

$4,405.9$

$1,400.2$

Auto Theft

$1,075.8$

702.3

$\underline{\text { Minimum }}$

$\underline{\text { Maximum }}$

Arrest Rate (Arrests/Reported Crimes)

Murder

Rape

Robbery

Agg. Assault

Burglary

Larceny

Auto Theft
0.823

0.390

0.265

0.419

0.128

0.184

0.127
0.190

0.187

0.110

0.207

0.053

0.060

0.072
0.6

6.7

25.8

42.3

610.8

848.1

164.6
80.6

199.3

$2,337.5$

$2,386.3$

$4,994.0$

$10,002.8$

$5,369.1$

\section{Other Variables}

Population

$\%$ Female Headed

Households

$\%$ Black

\% Age 15-24

Public Welfare

Spending Per Capita

Education
716,854

15.1

23.6

17.1

260.9

773.4
982,058

4.4

18.5

2.0

128.1

118.9
0.034

0.001

0.020

0.010

0.029

0.036

0.002
1.000

1.000

1.000

1.000

0.400

0.501

0.408

Spending Per Capita

Notes: Summary statistics are for annual data covering 59 large U.S. cities over the period 1971-1992. Crime rates are per 100,000 residents. Crime data from Uniform Crime Reports, published annually by the FBI. Arrest rates are unpublished FBI data. Demographic variables from The Statistical Abstract of the United States, except for city populations, from the FBI. In cases where the number of arrests exceeds the number of reported crimes, an arrest rate of one is assigned. Definitions of the crime categories are presented in the appendix. 
Table 2: Difference Estimators and Measurement Error in Arrest Rates Including Current Period Arrest Rate Only

$\begin{array}{llll}\text { First } & \text { Second } & \text { Third } & \text { Fourth } \\ \text { Diff. } & \text { Diff. } & \text { Diff. } & \text { Diff. }\end{array}$

\begin{tabular}{|c|c|c|c|c|}
\hline Murder & $\begin{array}{l}-.127 \\
(.045)\end{array}$ & $\begin{array}{l}-.030 \\
(.033)\end{array}$ & $\begin{array}{c}-.079 \\
(.034)\end{array}$ & $\begin{array}{c}-.094 \\
(.034)\end{array}$ \\
\hline Rape & $\begin{array}{l}-.093 \\
(.022)\end{array}$ & $\begin{array}{l}-.093 \\
(.017)\end{array}$ & $\begin{array}{c}-.089 \\
(.018)\end{array}$ & $\begin{array}{l}-.109 \\
(.016)\end{array}$ \\
\hline Assault & $\begin{array}{l}-.167 \\
(.034)\end{array}$ & $\begin{array}{l}-.169 \\
(.031)\end{array}$ & $\begin{array}{l}-.189 \\
(.034)\end{array}$ & $\begin{array}{l}-.160 \\
(.030)\end{array}$ \\
\hline Robbery & $\begin{array}{l}-.210 \\
(.030)\end{array}$ & $\begin{array}{l}-.294 \\
(.034)\end{array}$ & $\begin{array}{l}-.301 \\
(.030)\end{array}$ & $\begin{array}{l}-.313 \\
(.032)\end{array}$ \\
\hline Burglary & $\begin{array}{l}-.219 \\
(.028)\end{array}$ & $\begin{array}{l}-.253 \\
(.027)\end{array}$ & $\begin{array}{l}-.305 \\
(.028)\end{array}$ & $\begin{array}{r}-.319 \\
(.029)\end{array}$ \\
\hline Larceny & $\begin{array}{l}-.154 \\
(.021)\end{array}$ & $\begin{array}{l}-. .204 \\
(.023)\end{array}$ & $\begin{array}{l}-.239 \\
(.024)\end{array}$ & $\begin{array}{l}-.266 \\
(.024)\end{array}$ \\
\hline Auto Theft & $\begin{array}{l}-.099 \\
(.019)\end{array}$ & $\begin{array}{l}-.086 \\
(.019)\end{array}$ & $\begin{array}{l}-.074 \\
(.021)\end{array}$ & $\begin{array}{l}-.066 \\
(.023)\end{array}$ \\
\hline
\end{tabular}

Notes: Values in the table are the elasticities of reported crime with respect to the arrest rate for the listed crime category. Arrest rates are defined as arrests per crime. The sample used is annual data for 59 large U.S. cities for the period 1970-1992. The number of observations ranges from 819 to 991 depending on the particular crime category and the length of the difference employed. White heteroskedasticity-consistent standard errors in parentheses. In the presence of measurement error in the dependent variable, the coefficients should become less negative moving from left to right across columns. In addition to arrest rates, the other covariates included in the regressions are city population, percent of female-headed households, percent black, state and local spending on education, state and local spending on public welfare, state unemployment rate, percent of the population between the ages of 15 and 24 , and year dummies. 
Table 3: Difference Estimators and Measurement Error in Arrest Rates Including current period and once-lagged arrest rates

$\begin{array}{llll}\text { First } & \text { Second } & \text { Third } & \text { Fourth } \\ \text { Diff. } & \text { Diff. } & \text { Diff. } & \text { Diff. }\end{array}$

(1)

$\begin{array}{lllll}\text { Murder } & -.071 & -.029 & -.011 & -.043 \\ & (.072) & (.044) & (.037) & (.052) \\ \text { Rape } & -.119 & -.092 & -.099 & -.110 \\ & (.030) & (.021) & (.025) & (.022) \\ \text { Assault } & -.201 & -.189 & -.201 & -.209 \\ & (.047) & (.047) & (.046) & (.041) \\ \text { Robbery } & -.339 & -.348 & -.362 & -.339 \\ & (.053) & (.042) & (.037) & (.037) \\ \text { Burglary } & -.272 & -.288 & -.326 & -.345 \\ & (.036) & (.034) & (.034) & (.035) \\ \text { Larceny } & -.204 & -.225 & -.244 & -.260 \\ & (.030) & (.028) & (.027) & (.028) \\ \text { Auto Theft } & -.087 & -.060 & -.045 & -.041 \\ & (.028) & (.026) & (.027) & (.029)\end{array}$

Notes: Values in the table are the combined elasticities of reported crime with respect to the arrest rate and once-lagged arrest rate for the listed crime category. Arrest rates are defined as arrests per crime. The sample used is annual data for 59 large U.S. cities for the period 1970-1992. The number of observations ranges from 645 to 867 depending on the particular crime category and the length of the difference employed. White heteroskedasticity-consistent standard errors in parentheses. In the presence of measurement error in the dependent variable, the coefficients should become less negative moving from left to right across columns. In addition to arrest rates, the other covariates included in the regressions are city population, percent of female-headed households, percent black, state and local spending on education, state and local spending on public welfare, state unemployment rate, percent of the population between the ages of 15 and 24 , and year dummies. 
Table 4: The Effect of Arrest Rates Across Crimes on Crime Rates

\begin{tabular}{|c|c|c|c|c|c|c|c|}
\hline$\underline{\text { Variable }}$ & $\underline{\text { Murder }}$ & $\underline{\text { Rape }}$ & $\underline{\text { Robbery }}$ & Assault & Burglary & $\underline{\text { Larceny }}$ & Auto Theft \\
\hline $\log$ (Own-crime arrest rate) & $\begin{array}{c}0.012 \\
(0.045)\end{array}$ & $\begin{array}{l}-0.108 \\
(0.021)\end{array}$ & $\begin{array}{l}-0.332 \\
(0.038)\end{array}$ & $\begin{array}{l}-0.167 \\
(0.030)\end{array}$ & $\begin{array}{l}-0.312 \\
(0.028)\end{array}$ & $\begin{array}{l}-0.288 \\
(0.023)\end{array}$ & $\begin{array}{l}-0.074 \\
(0.023)\end{array}$ \\
\hline $\begin{array}{l}\log \text { (Non-substitutable crime } \\
\text { arrest rate) }\end{array}$ & $\begin{array}{l}-0.040 \\
(0.058)\end{array}$ & $\begin{array}{l}-0.166 \\
(0.045)\end{array}$ & $\begin{array}{l}-0.156 \\
(0.045)\end{array}$ & $\begin{array}{l}-0.020 \\
(0.055)\end{array}$ & $\begin{array}{l}-0.012 \\
(0.025)\end{array}$ & $\begin{array}{l}-0.029 \\
(0.023)\end{array}$ & $\begin{array}{l}-0.055 \\
(0.045)\end{array}$ \\
\hline $\begin{array}{l}\log \text { (Substitutable crime } \\
\text { arrest rate) }\end{array}$ & $\begin{array}{l}-0.129 \\
(0.040)\end{array}$ & $\begin{array}{l}-0.010 \\
(0.030)\end{array}$ & $\begin{array}{c}0.062 \\
(0.030)\end{array}$ & $\begin{array}{l}-0.024 \\
(0.051)\end{array}$ & $\begin{array}{l}-0.062 \\
(0.026)\end{array}$ & $\begin{array}{c}0.048 \\
(0.023)\end{array}$ & $\begin{array}{l}-0.298 \\
(0.048)\end{array}$ \\
\hline \% Female-Headed Households & $\begin{array}{c}0.020 \\
(0.011)\end{array}$ & $\begin{array}{c}0.068 \\
(0.011)\end{array}$ & $\begin{array}{c}0.004 \\
(0.010)\end{array}$ & $\begin{array}{l}-0.005 \\
(0.011)\end{array}$ & $\begin{array}{c}0.020 \\
(0.007)\end{array}$ & $\begin{array}{r}0.007 \\
(0.007)\end{array}$ & $\begin{array}{c}0.029 \\
(0.013)\end{array}$ \\
\hline$\%$ Black & $\begin{array}{c}0.012 \\
(0.005)\end{array}$ & $\begin{array}{c}0.006 \\
(0.005)\end{array}$ & $\begin{array}{c}0.018 \\
(0.005)\end{array}$ & $\begin{array}{c}0.000 \\
(0.006)\end{array}$ & $\begin{array}{c}0.003 \\
(0.003)\end{array}$ & $\begin{array}{r}-0.002 \\
(.003)\end{array}$ & $\begin{array}{l}-0.006 \\
(0.005)\end{array}$ \\
\hline$\%$ Age $15-24$ in SMSA & $\begin{array}{c}0.011 \\
(0.020)\end{array}$ & $\begin{array}{l}-0.069 \\
(0.017)\end{array}$ & $\begin{array}{c}0.091 \\
(0.017)\end{array}$ & $\begin{array}{c}0.043 \\
(0.024)\end{array}$ & $\begin{array}{l}-0.023 \\
(0.013)\end{array}$ & $\begin{array}{c}0.032 \\
(0.011)\end{array}$ & $\begin{array}{c}0.053 \\
(0.023)\end{array}$ \\
\hline $\begin{array}{l}\log \text { (Public welfare spending } \\
\text { per capita) }\end{array}$ & $\begin{array}{l}-0.098 \\
(0.062)\end{array}$ & $\begin{array}{c}0.161 \\
(0.046)\end{array}$ & $\begin{array}{l}-0.131 \\
(0.043)\end{array}$ & $\begin{array}{c}0.135 \\
(0.051)\end{array}$ & $\begin{array}{c}0.050 \\
(0.036)\end{array}$ & $\begin{array}{c}0.002 \\
(0.029)\end{array}$ & $\begin{array}{l}-0.181 \\
(0.057)\end{array}$ \\
\hline $\begin{array}{l}\log \text { (Education spending } \\
\text { per capita) }\end{array}$ & $\begin{array}{c}0.048 \\
(0.165)\end{array}$ & $\begin{array}{c}0.616 \\
(0.123)\end{array}$ & $\begin{array}{c}0.512 \\
(0.111)\end{array}$ & $\begin{array}{c}0.157 \\
(0.171)\end{array}$ & $\begin{array}{c}0.437 \\
(0.100)\end{array}$ & $\begin{array}{c}0.307 \\
(0.076)\end{array}$ & $\begin{array}{r}0.249 \\
(0.127)\end{array}$ \\
\hline State unempioyment rate & $\begin{array}{l}-1.880 \\
(0.687)\end{array}$ & $\begin{array}{l}-2.234 \\
(0.540)\end{array}$ & $\begin{array}{c}0.542 \\
(0.570)\end{array}$ & $\begin{array}{l}-2.012 \\
(0.641)\end{array}$ & $\begin{array}{c}3.239 \\
(0.429)\end{array}$ & $\begin{array}{c}2.323 \\
(0.352)\end{array}$ & $\begin{array}{c}0.888 \\
(0.738)\end{array}$ \\
\hline $\log$ (City population) & $\begin{array}{c}1.204 \\
(0.105)\end{array}$ & $\begin{array}{c}1.076 \\
(0.078)\end{array}$ & $\begin{array}{c}1.330 \\
(0.067)\end{array}$ & $\begin{array}{c}0.859 \\
(0.077)\end{array}$ & $\begin{array}{c}0.855 \\
(0.052)\end{array}$ & $\begin{array}{c}0.868 \\
(0.041)\end{array}$ & $\begin{array}{c}1.367 \\
(0.080)\end{array}$ \\
\hline Adjusted $R^{2}$ & 0.955 & 0.948 & 0.971 & 0.943 & 0.961 & 0.971 & 0.948 \\
\hline
\end{tabular}

Notes: Dependent variable is the natural log of the named crime category. The sample covers the period 1970-1992 for 59 large U.S. cities. Coefficients on arrest rates are the sums of the contemporaneous and once-lagged values. City-fixed effects, city trends, and year dummies included in all regressions. White-heteroskedasticity consistent standard errors in parentheses. Coefficients on arrest rates are elasticities. Number of observations is 963 in all columns. The coefficient on non-substitutable crimes should reflect only incapacitation effects, whereas the other arrest coefficients reflect both incapacitation and deterrence effects. Violent and property crimes are treated as non-substitutes. All violent crimes are treated as substitutes for one another; likewise, all property crimes are treated as substitutes for one another. 
(1)

\begin{tabular}{l} 
Crime \\
Category \\
\hline
\end{tabular}

Murder

Rape

Robbery

Aggravated

Assault

Burglary

Larceny/

Auto Theft

84.1
(2)

(3)

Relative \# of
Adjudicated

Reiative

\# of Arrests

1.0

1.0

1.4

8.4

11.8

10.0

14.1

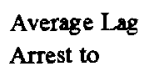

Sentencing (Days)

347

254

0.46

Fraction
Detained
Pre-trial

Mean Pre-Trial
Time Served

Per Arrest

232

Fraction of

Defendants

Convicted

0.61

Post-Sentence

Time Served

Total

Time-Served

per Arrest

0.67

207

439

99

0.56

159

258

210

0.49

101

0.60

187

288

31

0.46

69

100

176

0.44

42

0.68

72

114

185

0.33

10

29

39

Notes: All calculations based on information contained in Felony Defendants in Large Urban Counties, 1990. All values for time served reflect only time served within two calendar years of arrest. Columns 1 and 2 are relative to the number of murder arrests and murder felony defendants respectively. The values in the table assume that all murder arrests lead to prosecution. A small fraction of property crime arrests are prosecuted as misdemeanors, but in the large majority of arrests that do not lead to felony defendants, charges are dropped. Column 5 is calculated as the product of columns 2,3 , and 4 , divided by column 1 to normalize for the number of arrests. Column 7 assumes that convicted felons serve out whatever time remains in the calendar year following arrest. 
Table 6: Likelihood of Re-Arrest within 3 Years of Release by Previous Offense

Source: Beck (1989)

Most Serious Previous Offense:

$\%$ Arrested

w/i 3 years of

release for:

Murder

Rape

Robbery

Agg. Assault

Burglary

Larceny

Auto Theft
Named

Offense

6.6

7.7

21.9

19.6

31.9

33.5
Other

Violent

Offenses

2.6

1.3

14.7

8.4

13.3

17.3

25.4

4.2

Other

1.0

0.6

11.7

9.2

18.7

6.7
Property

Offenses

18.6

Notes: Information in table is computed using data in Table 9 of Beck (1989), an analysis of recidivism patterns of more than 16,000 prisoners released in 1983. Previous arrest category corresponds to the most serious offense at time of release. All rearrests within three years are included in the recidivism figures. Recidivism data based on arrest records from all 50 U.S. states and the FBI. 
Change in Number of Crimes within

$$
\text { Category Per Arrest for: }
$$

\section{Crime}

Category

Murder

\begin{tabular}{|c|c|}
\hline This Crime & $\begin{array}{l}\text { Non-Substitutable } \\
\text { Crime Categories }\end{array}$ \\
\hline $\begin{array}{c}0.015 \\
(0.056)\end{array}$ & $\begin{array}{l}-0.0006 \\
(0.0009)\end{array}$ \\
\hline
\end{tabular}

Rape

$-0.277$

(0.054)

$-0.009$

(0.002)

Robbery

$-1.253$

(0.143)

$-0.071$

$(0.020)$

Aggravated

$-0.399$

(0.072)

$-0.009$

(0.025)

Burglary

$-2.438$

(0.219)

$-0.067$

$(0.140)$

Larceny

$-1.565$

(0.125)

$-0.308$

$(0.244)$

Auto Theft
$-0.583$

$(0.181)$
$-0.143$

(0.117)
(3)

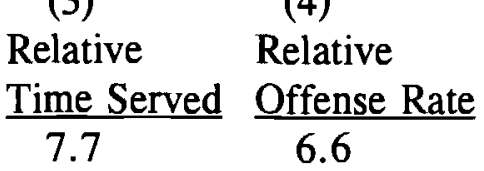

1.8

0.6

0.2

0.2
Change in Crimes Per own-Arrest via:

(5)

(6)

\begin{tabular}{cc} 
Deterrence & Incapacitation \\
\hline 0.045 & -0.030 \\
$(0.076)$ & $(0.046)$
\end{tabular}

$0.241 \quad-0.518$

(0.162) (0.141)

$\begin{array}{ll}-0.565 & -0.688\end{array}$

(0.291) (0.199)

$-0.365 \quad-0.034$

(0.122) (0.094)

$-2.342 \quad-0.096$

$(0.355) \quad(0.200)$

$-1.448 \quad-0.117$

(0.162) (0.093)

$-0.457 \quad-0.126$

$(0.225) \quad(0.103)$

Notes: Results in table are based on coefficient estimates reported in Table 4 and the information in Tables 5 and 6 from Felony Defendants in Large Urban Counties and Beck (1989), respectively. Values in this table are evaluated at the sample means reported in Table 1. Column (1) is the change in crime with a one-arrest increase in the own crime, and reflects both deterrence and incapacitation effects. Column (2) is the cross-crime elasticity of arrests for "non-substitutable" crimes. Property crimes are assumed to be "non-substitutable" for violent crimes and vice-versa. Columns 3 and 4 are based on Tables 5 and 6 respectively and reflect the relative values for the crime in question vis-a-vis the non-substitutable crimes. For instance, murderers serve an average of 7.7 times as many months behind bars per arrest as property offenders, and murderers are 6.6 times more likely than property offenders to commit a murder within three years of release from prison. Columns 5 and 6 translate the information in columns 1-4 using equations 13 and 12 to provide the estimated number of crimes within a category eliminated through deterrence (column 5) or incapacitation (column 6) per arrest. 


\section{Bibliography}

Andreoni, James, 1991, "Reasonable Doubt and the Optimal Magnitude of Fines:

Should the Penalty Fit the Crime?" RAND Journal of Economics 22:385-395.

Beck, Allen, 1989, "Recidivism of Prisoners Released in 1983," Bureau of Justice Statistics Special Report.

Becker, Gary, 1968, "Crime and Punishment: An Economic Approach," Journal of Political Economy 76:169-217.

Benson, Bruce, Iiljong Kim, and David Rasmussen, 1995, "Deterrence and Public Policy: Trade-offs in the Allocation of Police Resources," Mimeo, Florida State University Department of Economics.

Blumstein, Alfred, Daniel Nagin, and Jacqueline Cohen (eds.), 1978, Deterrence and Incapacitation: Estimating the Effects of Criminal Sanctions on Crime Rates, Wash DC: National Academy of Sciences.

Blumstein, Alfred, Jacqueline Cohen, Jeffrey Roth, and Christy Visher (eds.), 1986, Criminal Careers and 'Career Criminals', Wash DC: National Academy of Sciences.

Bureau of Justice Statistics, 1994, Criminal Victimization in the United States, 1992, Wash DC: Department of Justice.

Cameron, Samuel, 1988, "The Economics of Crime Deterrence: A Survey of Theory and Evidence," Kyklos 41:301-323.

Dilulio, John, and Anne Piehl, 1991, "Does Prison Pay? The Stormy National Debate over the Cost-Effectiveness of Imprisonment," The Brookings Review (fall), 28-35.

Donohue, John, and Peter Siegelman, 1994, "Is the United States at the Optimal Rate of Crime?" Mimeo, American Bar Foundation.

Ehrlich, Isaac, 1973, "Participation in Illegitimate Activities: A Theoretical and Empirical Investigation," Journal of Political Economy 81:531-567.

Ehrlich, Isaac, 1981, "On the Usefulness of Controlling Individuals: An Economic Analysis of Rehabilitation, Incapacitation, and Deterrence, American Economic Review 71:307322.

Gibbs, Jack, and Glenn Firebaugh, 1990, "The Artifact Issue in Deterrence Research," Criminology 28:347-367.

Griliches, Zvi, and Jerry Hausman, 1986, "Errors in Variables in Panel Data," Journal of 


\section{Econometrics 31:93-118.}

Grogger, Jeff, 1991, "Certainty vs. Severity of Punishment," Economic Inquiry 29: 297-309.

Levitt, Steven, 1994, "The Response of Crime Reporting Behavior to Changes in the Size of the Police Force: Implications for Studies of Police Effectiveness using Reported Crime Data," Mimeo, Harvard University.

Levitt, Steven, 1995, "Using Electoral Cycles in Police Hiring to Estimate the Effect of Police on Crime," Mimeo, Harvard University.

McCormick, Robert, and Robert Tollison, 1984, "Crime on the Court," Journal of Political Economy 92:223-235.

Myers, S., 1983, "Estimating the Economic Model of Crime: Punishment vs. Deterrent Effects," Quarterly Journal of Economics 98:157-166.

Piehl, Anne, and John Dilulio, 1995, "Does Prison Pay? Revisited," The Brookings Review, (winter), 21-25.

Polinsky, A. Mitchell, and Steven Shavell, 1984, "The Optimal Use of Fines and Imprisonment," Journal of Public Economics 24:89-99.

Posner, Richard, 1977, Economic Analysis of Law, Boston: Little-Brown.

Spelman, William, 1994, Criminal Incapacitation, New York: Plenum.

Stigler, George, 1970, "The Optimum Enforcement of Laws," Journal of Political Economy 78:526-536.

Tauchen, Helen, Ann Witte, and Harriet Griesinger, 1993, "Criminal Deterrence: Revisiting the Issue with a Birth Cohort," NBER working paper no. 4277.

Trumbull, William, 1989, "Estimations of the Economic Model of Crime Using Aggregate and Individual Level Data," Southern Economic Journal 94:423-439.

Venkatesh, Sudhir, 1994, "Learnin' the Trade: Conversations with a Gangsta', " Public Culture 6:319-341.

Visher, Christy, 1986, "The RAND Inmate Survey: A Reanalysis," in Blumstein, A. et al. (eds.), Criminal Careers and "Career Criminals." Volume II, National Academy Press: Washington, D.C.

Waldfogel, Joel, 1993, "Criminal Sentences as Endogenous Taxes: Are They 'Just' or 'Efficient'?" Journal of Law and Economics 36:139-151. 
Wilson, James Q., and Richard Herrnstein, 1985, Crime and Human Nature, New York: Simon and Schuster.

Witte, Ann, 1980, "Estimating the Economic Model of Crime with Individual Data," Quarterly Journal of Economics 94:57-84 